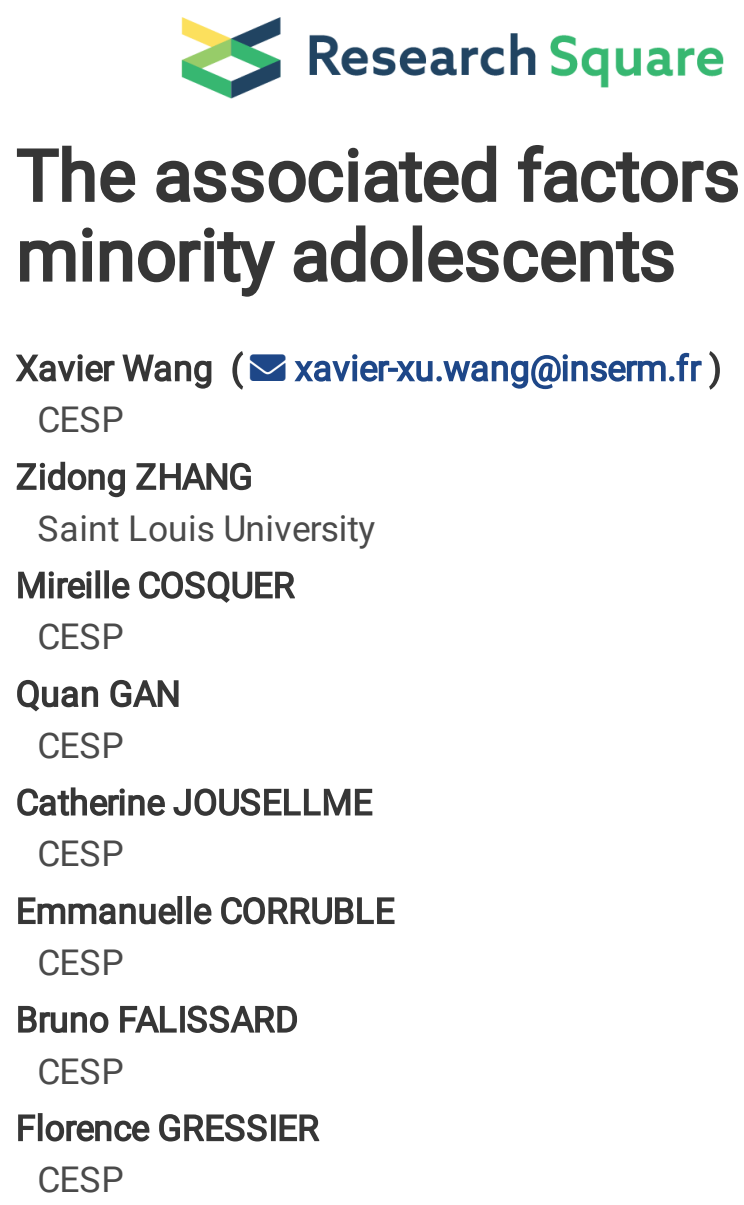

\title{
The associated factors of suicide attempt in French sexual minority adolescents
}




\section{Abstract}

BACKGROUND: Sexual minority adolescents have greater risk for suicide attempt than heterosexual youth. However, research on risk and protective factors is lacking in sexual minority youth. In this study, we aimed to identify novel risk and protective factors for suicide attempt using machine learning decision tree method.

METHODS: The French cross-sectional study “Portraits adolescents" included 14265 school-age adolescents. Decision tree algorithm was used to predict SA and to compare the different risk and protective factors between sexual minority youth and heterosexual peers.

RESULTS: Twenty predictive factors were identified among the 70 survey fields output from the predictive modeling for SA. Substance consumptions were among the top risk factors for SA. Parental support was an important protective factor among all adolescents regardless of sexual orientation. Interestingly, through the decision tree, real-life friend support was found protective in heterosexual youth, online friend support was a protective factor in homosexual adolescents.

CONCLUSIONS: Using the decision tree-based algorithm, we not only verified those important protective factors that were demonstrated in existing studies, but also discovered novel protective and attributive factors, such as real-life and online friend support. We urge that social networks should be optimize to provide safety and support for the sexual minority adolescents.

\section{Introduction}

Suicide among adolescents is a worldwide major public health problem ${ }^{1}$. In the United States, it is the second leading cause of death among youth aged 10-24 since year 2011, and cost 6000 lives per year from 2011 to $2019^{2}$. In France, suicide is the second leading cause of death for 15-24 years old, with more than $16 \%$ of deaths in this age group in $2014{ }^{3}$. One of the main risk factors for death by suicide among adolescents and young adults is a history of suicide attempts ${ }^{4}$. In 2014 , one in ten young people said they had thought about suicide at least once in the past 12 months, and nearly $3 \%$ had already made a suicide attempt in their lifetime that required hospitalization ${ }^{5}$.

Suicide attempts (SA) among adolescents have been found multifaceted. Existing studies identified demographic and socioeconomic characteristics could predict high risk of SA, such as non-Caucasian race and Hispanic ethnicity in the North America ${ }^{6}$, care by single parents or non-parent guardians ${ }^{7}$. Some also found SA associated with individual mental health experiences, for which having negative ideas ${ }^{8}$, experiencing depressive episodes ${ }^{9}$, and substance uses may confer higher risks while support from parents may reduce the risk of SA among adolescents ${ }^{10}$. Besides, sexual orientation was found strongly associated with SA in recent years across the globe. Many studies demonstrated higher risks of SA among the sexual minority adolescents compared to the heterosexual counterparts, ranging from 2 to 5 times ${ }^{11-15}$. With the consensus that non-heterosexual adolescents had high risk of suicide, it remains uncertain whether sexual orientation can independently predict SA with or without interacting with other factors like socioeconomic factors and social experiences.

From the perspective of suicide prevention, it is crucial to find the risk and protective factors with the strongest predictability among adolescents of sexual minority. Although many risk factors for SA have been identified in this population as gender female, feel of insecurity at school, consumption of substances ${ }^{7,15-18}$, little is known on risk and protective factors in sexual minority youth. Moreover, specific protective factors also need to be identified in sexual minority youths. Existing studies reporting risk and protective factors for SA using conventional approaches like regression modeling are difficult to use, mainly due to methodological limitations, to develop preventive interventions ${ }^{19}$. Therefore, we performed machine learning-based algorithms to predict $\mathrm{SA}^{20}$. Such research could help to develop preventive interventions ${ }^{21,22}$. 
The aim of this study was to identify potential risk and protective factors of SA among the adolescents of sexual minority using decision tree-based algorithm. Through this approach, we expected to find new factors of SA specifically among adolescents of sexual minority based on primarily collected data. Therefore, appropriate interventions can be accurately and timely implemented to those adolescents having higher risks to alert and prevent potential SA.

\section{Materials And Methods}

French adolescents aged 13 to 20 years old were included in this study based on a cross-sectional survey database of Portraits d'adolescents ${ }^{23}$. This survey was collaborated between the Departments of National Education and Agricultural Education of France, Fondation Vallée Hospital, and INSERM UMR 1178. To summarize, the survey was conducted in 2013 in 3 French contrasted areas (Haute Alpes, Val de Marne, and Poitou-Charentes). 134 institutions were selected from these areas, representing a total of 730 classes. All students from the selected classes were enrolled in the survey ${ }^{23}$.

\section{Time frame of survey}

The survey was conducted simultaneously in all the sampling area in the week of October 14, 2013. In each area, trained staff was deployed to the participating institutions to disseminate and collect survey responses on site. The responses were anonymous and confidential. The survey and the current study were approved by Commission of National Information and Liberty (CNIL Protocol No. 912523). Because no intervention was involved, no additional approval was required according to French law.

\section{Inclusion \& exclusion criteria of participants}

The students aged 13-20 years studying in the participating institutions were enrolled in this study and provided response to the questionnaire on site when the survey staff worked in the institutions. The students older than 18 years old could refuse to participate in this survey after receiving the information letter. Parental consent has been requested for minors (less than 18 years old). Those adolescents who were out-of-school, or hospitalized in psychiatry or other services, or young people supported and educated in the medico-social were excluded.

\section{Measurements}

History of SA was the primary outcome, which was defined whether the participant attempted suicide at least once in the past. We asked 70 questions in the following 8 categories, constituting the explanatory and potential confounding variables of analyses.

Sociodemographic: age; gender assigned at birth; sexual orientation; and region (urban, semi-urban and rural area).

Family characteristics: parents' highest education level; parents' professions; parental separation; loss of parent(s); suicide of family members; living with parents; parental support; easily talking about personal problems in family; whether participant thinks mother is very beautiful; whether participant thinks father is very handsome; quarrels/fights between parents.

School experience: grade in which participant was; whether participant has repeated one year; whether participant likes to go to school.

Support from relationships: real-life friend support; online friend support, number of friends; whether participant have met online friends in life; whether participant belief that real-life friend is more important than online friend. 
Personal life: whether participant focus on physical appearance; whether participant always looks at self in mirror; how participant thinks when they look at themselves in mirror; which part of body not satisfy participant; whether participant avoids to reveal body to others; whether participant pays attention to what participant eat; whether participant has fallen in love; whether participant has dredged; whether participant has had sex experience; whether participant has used oral contraceptives; condoms or other contraceptive approaches during sex.

Mental health: whether eating is a pleasure; whether participant has suffered from overeating; whether participant has suffered from anorexia; whether participant has some questions to ask to themselves or the person around; participation in dangerous games; considering adolescence as an easy period.

Consumption of substances: smoking (during last 30 days); smoking intensively (at least ten cigarettes per day); drinking (during last 30 days); drinking regularly (at least 10 times during last 30 days); drunk (5 glasses per time during last 30 days); drunk often (at least 10 times during last 30 days); use of cannabis (during last 30 days); use of cannabis regularly (consumption of 10 times during last 30 days); and use of other drugs (amphetamine; inhaler; ecstasy; lysergic acid diethylamide [LSD]; crack; cocaine; heroin; Hallucinogenic mushroom; or methylenedioxymethamphetamine [MDMA]); consume alcohol with cannabis; consume alcohol with drugs

Health condition: BMI (Body Mass Index); whether participant has had a period of overweight; satisfaction of health; easy to tell the health problem with a doctor; easy to tell the health problem with father; easy to tell the health problem with mother; have another close adult person to talk about health problem.

\section{Analytic method}

First, we used the one-way chi-square test to compare the demographic characteristics Second, we applied the decision treebased predictive algorithm, a machine learning-based approach, to identify risk factors for SA based on the value of split rules while avoiding overfit of models or imposing an explanatory structure between predictors and outcomes ${ }^{24,25}$. Third, to estimate the effects of the risk factors identified from the decision tree-based modeling, we conducted single logistic regression models to predict SA based three subgroups (heterosexual, homosexual and bisexual). Estimate of effects from logistic regression models were displayed in odds ratio $(\mathrm{OR})$ and $95 \%$ confidence interval $(\mathrm{Cl})$. The machine-learning computations and logistic regression were conducted using SAS Studio 9.4 (SAS Institute, Cary, NC, USA). Statistical significance was determined with a two-tail $p$ value less than 0.05 for descriptive statistics and regression models.

\section{Results}

\section{Characteristic of participants}

Among all the participants, 14,265 aged 13 to 20 have answered the question of sexual orientation. They were classified into 3 groups: homosexuals $(209,1.5 \%)$, bisexuals $(428,3 \%)$ and heterosexuals $(13,628,95.5 \%)$ (Table 1$)$. Most of the students were in ages of 13 to 16 years (71.7\%), studying in high school (65.5\%) and female (52.2\%). As for the geographic origins, $46.4 \%$ of the students were from Hautes-Alpes (semi-urban), 26.8\% from Val de Marne (urban), and 26.8\% from Poitou-Charentes (rural). Several demographic characteristics varied between homosexual, bisexual and heterosexual subjects. The bisexual subjects were more likely to be female ( $73.6 \%$ vs. $67 \%$ homosexual vs. $51.3 \%$ heterosexual, $\mathrm{p}<0.0001)$, and mostly have repeated a school year ( $39.3 \%$ vs. $34 \%$ homosexual vs. $31.3 \%$ heterosexual, $p<0.001)$ whereas homosexual youth were the most likely in high schools (79.4\% vs. $75.9 \%$ bisexual vs. $65.0 \%$ heterosexual, $p<0.001)$. According to suicide attempts, the bisexual subjects reported the highest rate (36.2\% vs. $19.4 \%$ homosexual vs. $10.6 \%$ heterosexual, $p<0.0001$ ).

\section{Predictive factors selected from decision tree-based algorithms to predict SA}


The decision tree was based on the whole sample data comprising of 70 variables including sexual orientation. We tested our model with several sets of parameters and obtained the best goodness of fit when the cost-complexity pruning method was used as subtree evaluation criterion and the number of leaves after pruning was 30 . The minimum average misclassification rate is 0.120 (Figure 1.A) and the Area under the receiver operating characteristics curve (AUC-ROC) is 0.87 (Figure 1.B). In the model, 20 predictive factors were identified by the value of relevance and efficacy, in which sexual orientation was output from the variable selection (Table 2).

As demonstrated in the flow of decision tree (Figure 2), the data was split into a series of dichotomous partitions. At each partitioning, non-missing data entered either of the two branches while missing was dropped from the tree. In this way, data input in the tree was processed until a maximal tree was formed. As the formation of tree proceeded along the series of partitions, the cumulative probability of SA rose in the branch indicating SA while the cumulative probability of not-SA rose in the counterpart direction

\section{Quantification of effects of predictors output from the decision tree models}

The 20 predictive variables from the predictive modeling for SA were classified into 6 categories, namely, demographics, relations, personal life, mental health, consumption of substances and health condition. We input these variables, except sexual orientation, in single logistic regression models to estimate the effects of each variable on the heterosexual, the homosexual, and the bisexual subsets, respectively (Table 3).

Among the homosexual subjects, 6 protective factors (parental support, have met some online friends in life, online friend support, belief that eating is pleasure, satisfaction of health, belief that talking about health is easier with mother ) were found associated with SA while another 7 risk factors (participated in dangerous games, dissatisfaction with some body, consume alcohol with drugs, history of cocaine use, history of ecstasy use, history of amphetamine use, intensive use of tobacco parts ) found inversely associated (Table 3).

Among the bisexual subjects, 5 protective factors (parental support, belief that adolescence is an easy period, belief that eating is pleasure, satisfaction of health, belief that talking about health is easier with mother) were found associated with SA while 6 risk factors (participated in dangerous games, consume alcohol with drugs, history of cocaine use, history of ecstasy use, history of amphetamine use, intensive use of tobacco) were identified (Table 3). Interestingly, online friend support did not appear a protective factor among bisexuals.

In heterosexual group, 7 factors (parental support, have met some online friends in life, real-life friend support, belief that adolescence is an easy period, belief that eating is pleasure, satisfaction of health, belief that talking about health is easier with mother) were identified as protective factors of SA while 11 factors (gender, living with parents, first sexual activity, participated in dangerous games, dissatisfaction with some body parts, when you look at yourself in a mirror you are not happy, consume alcohol with drugs, history of cocaine use, history of ecstasy use, history of amphetamine use, intensive use of tobacco) were risk factors (Table 3).

\section{Discussion}

In our study, we confirmed the high rates of SA among LGB adolescents, compared to the heterosexual counterparts, and further differentiated the predictiveness for SA by sexual orientation.

In our study, consumptions of alcohol and substances were among the top three risk factors for SA in all sexual orientations. Jiang et al. found that in North America consumption of alcohol was associated with SA especially drinking alcoholic beverages mixed with drugs like marijuana ${ }^{26}$. This point was consistent with our result that the consumption of alcohol with drugs could independently predict SA apart from sexual orientation. Moreover, we implied from our result that consumption of other illicit drugs for entertainment could be additive in terms of odds of SA among both LGB and 
heterosexual adolescents. Very few studies gave the comprehensive consideration of and contrast the consumptions of any possible substances among adolescents in France and Western Europe in existing literature. The simultaneous use of alcohol and drugs often leads to high-risk behaviors because it accelerates and enhances the pharmacological effects of substances ${ }^{27}$. In addition to substance consumption, dissatisfaction with some body parts is also identified as an important risk factor. It also could be a more direct way for teenagers to express their self-criticism as pointed out in other studies, which is considered to be a suicide-related factor 28,29 .

Considering protective factors, support from parents is considered as one of the strongest protective factors of SA in all of adolescents in this study, which reveals the importance role of family. A recent study found that the high satisfaction of family relationship and of personal health were both protective for suicidality (Bae et al., 2019), which was consistent with our finding. In addition, we found that online friend support was a protective factor only in homosexuals whereas real-life friend support was a protective factor in heterosexuals. Among the current literature, we only found two studies pertaining to friends support, in which online friendship were found to be used often by LGBT youth in complement to "perceived limitations in offline resources and relationships" 30 and LGB youth were more likely than non-LGBT youth to think "these friends as better than their in-person friends at providing emotional support" ${ }^{31}$. In the past decade, since adolescents have got to spend much more time online, they are more exposed to support and help from Internet. But Dehaan et al. also pointed out that the relations between online friends or even romantic partners among LGB youth was more difficulty to sustain compared to those made through offline contact ${ }^{30}$. These findings suggest that online friends can be an important source of social support, particularly for LGB youth.

Based on the risk and protective factors reported, we propose the following suicide prevention strategies:

1. Family plans for sexual minorities can be the focus of future development, because LGB adolescents face an environment in their family settings that they have no right to choose and little power to change. Sexual orientation related SA was more open about being LGB with their families, had been often called "sissy" or "tomboy" 32 , concealing one's homosexual identity may be less harmful than disclosing it ${ }^{33}$. It is important to encourage positive family relationships and parental support, so that these young people know they have the opportunity to disclose their sexual orientation or gender identity in a positive and safe environment. Interventions with parents can take the form of twinning programs that allow them to share their experiences, to benefit from attentive listening and to learn more about sexual diversity.

2. Friends of Lesbians and Gays and Gay-Straight Alliance groups should be built 9,34 to strengthen the relationships between LGB adolescents and their heterosexual peers. Led by the education system, in line with the policies of the health administrative department, the aim is to increase communication between heterosexual and sexual minority students, to strengthen education of all students, and deepen the knowledge of coming out, sexual orientation and gender identity. For LGB youth who have locate in unsupportive environment, having positive resources and healthy support systems may literally be the effective prevention of SA.

3. The optimal Internet resources for suicide prevention and protection could be created. Sexual minority youths are more accustomed to relying on the online world, we should establish website resources (The Trevor Project ${ }^{35}$, a 24/7 hotline for LGBT suicidal youth; the It Gets Better Project ${ }^{36}$, a 24/7 hotline for LGBTQ people who are in crisis) to prevent sexual minority youths from committing suicide.

\section{Limitations and strengths}

This study has some limitations. First, since decision tree requires a dichotomous split at each branch, we need to convert a few ordinal variables to binary way, indicating possible misclassification. Second, this study used cross-sectional data to explore predictors of SA, which cannot generate causal relations. Third, the retrospective data that used in this study might cause some recall bias from self-reporting of subjects' previous experiences. Last, we were unable to collect data about 
race/ethnicity, religious affiliation, bullying/being bullied, physical and sexual abuses on the adolescents due to the French regulations. Yet, we acknowledged race/ethnicity- and religious belief-specific variations in perception of sexual minority and suicidal behaviors.

Our study also has several strengths. First, decision tree-based algorithm can identify predictors without need to address challenges for regression modeling in the high dimensional data, such as multicollinearity, missing data and complex intervariable relations. It may provide high sensitivity and specificity to predict outcomes from real-world clinical data. Thus, this approach has a great potential to be developed to real-time risk monitoring tools in clinical circumstances for adverse outcome prevention. Second, while most existing studies emphasized male subjects, our study slightly oversampled female subjects between 13 and 20 years old. This might better portray the associations for female subjects.

\section{Conclusions}

We explored the decision tree-based approach to predict SA from a primarily collected data of SA in France. Using the decision tree-based algorithm, we not only verified those important protective factors that were demonstrated in existing studies, such as parental support, but also discovered novel protective and attributive factors, such as real-life and online friend supports, and their strengths in affecting SA. We urge that social networks should be optimized to provide safety and support for the sexual minority adolescents. Future research will lie in the development of real-time prediction tools and the expansion of modeling from including time-dependent variables.

\section{Declarations}

Conflicts of interest. $3 / 4$ The authors certify that there is no conflict of interest with any financial organization regarding the material discussed in the manuscript.

Funding. 3/4This research did not receive any specific funding.

Authors' contributions. $3 / 4 \mathrm{CJ}$ and $\mathrm{BF}$ designed the survey. $\mathrm{CJ}$ and $\mathrm{MC}$ conducted the survey. $\mathrm{XW}, \mathrm{ZZ}, \mathrm{QG}$ and FG conceived the idea, analyzed and interpreted the data, drafted the manuscript. ZZ and XW planned the manuscript and the statistical analysis. EC, MC, FG, BF and CJ reviewed the manuscript and gave critically constructive revisions. All authors read and approved the final manuscript.

\section{References}

1. Smith L, Jackson SE, Vancampfort D, et al. Sexual behavior and suicide attempts among adolescents aged 12-15 years from 38 countries: A global perspective. Psychiatry Research. 2020;287:112564. doi:10.1016/j.psychres.2019.112564

2. Centers for Disease Control and Prevention. Web-based injury statistics query and reporting system (WISQARS) [WWW Document]. Published online 2019. https://www.cdc.gov/injury/wisqars/LeadingCauses.html

3. Drees. Suicide: enjeux éthiques de la prévention, singularités du suicide à l'adolescence. Observatoire national du suicide. Published online 2018.

4. Castellví P, Lucas-Romero E, Miranda-Mendizábal A, et al. Longitudinal association between self-injurious thoughts and behaviors and suicidal behavior in adolescents and young adults: A systematic review with meta-analysis. Journal of Affective Disorders. 2017;215:37-48. doi:10.1016/j.jad.2017.03.035

5. Janssen E, Spilka S, Beck F. Suicide, santé mentale et usages de substances psychoactives chez les adolescents français en 2014. Revue d'Épidémiologie et de Santé Publique. 2017;65(6):409-417. doi:10.1016/j.respe.2017.06.004 
6. Toomey RB, Syvertsen AK, Flores M. Are Developmental Assets Protective Against Suicidal Behavior? Differential Associations by Sexual Orientation. Journal of Youth and Adolescence. 2019;48(4):788-801. doi:10.1007/s10964-018-0954y

7. Rimes KA, Shivakumar S, Ussher G, Baker D, Rahman Q, West E. Psychosocial Factors Associated With Suicide Attempts, Ideation, and Future Risk in Lesbian, Gay, and Bisexual Youth: The Youth Chances Study. Crisis. 2019;40(2):83-92. doi:10.1027/0227-5910/a000527

8. Mustanski B, Liu RT. A Longitudinal Study of Predictors of Suicide Attempts Among Lesbian, Gay, Bisexual, and Transgender Youth. Arch Sex Behav. 2013;42(3):437-448. doi:10.1007/s10508-012-0013-9

9. Taliaferro LA, Muehlenkamp JJ. Nonsuicidal Self-Injury and Suicidality Among Sexual Minority Youth: Risk Factors and Protective Connectedness Factors. Academic Pediatrics. 2017;17(7):715-722. doi:10.1016/j.acap.2016.11.002

10. Padilla YC, Crisp C, Rew DL. Parental Acceptance and Illegal Drug Use among Gay, Lesbian, and Bisexual Adolescents: Results from a National Survey. Social Work. 2010;55(3):265-275. doi:10.1093/sw/55.3.265

11. di Giacomo E, Krausz M, Colmegna F, Aspesi F, Clerici M. Estimating the Risk of Attempted Suicide Among Sexual Minority Youths: A Systematic Review and Meta-analysis. JAMA Pediatrics. 2018;172(12):1145.

doi:10.1001/jamapediatrics.2018.2731

12. Marshal MP, Dietz LJ, Friedman MS, et al. Suicidality and Depression Disparities Between Sexual Minority and Heterosexual Youth: A Meta-Analytic Review. Journal of Adolescent Health. 2011;49(2):115-123.

doi:10.1016/j.jadohealth.2011.02.005

13. Miranda-Mendizábal A, Castellví P, Parés-Badell O, et al. Sexual orientation and suicidal behaviour in adolescents and young adults: systematic review and meta-analysis. British Journal of Psychiatry. 2017;211(2):77-87.

doi:10.1192/bjp.bp.116.196345

14. Williams AJ, Jones C, Arcelus J, Townsend E, Lazaridou A, Michail M. A systematic review and meta-analysis of victimisation and mental health prevalence among LGBTQ+ young people with experiences of self-harm and suicide. De Luca V, ed. PLOS ONE. 2021;16(1):e0245268. doi:10.1371/journal.pone.0245268

15. Reisner SL, Biello K, Perry NS, Gamarel KE, Mimiaga MJ. A compensatory model of risk and resilience applied to adolescent sexual orientation disparities in nonsuicidal self-injury and suicide attempts. American Journal of Orthopsychiatry. 2014;84(5):545-556. doi:10.1037/ort0000008

16. Arnarsson A, Sveinbjornsdottir S, Thorsteinsson EB, Bjarnason T. Suicidal risk and sexual orientation in adolescence: A population-based study in Iceland. Scand J Public Health. 2015;43(5):497-505. doi:10.1177/1403494815585402

17. Hidaka Y, Operario D, Takenaka M, Omori S, Ichikawa S, Shirasaka T. Attempted suicide and associated risk factors among youth in urban Japan. Soc Psychiat Epidemiol. 2008;43(9):752-757. doi:10.1007/s00127-008-0352-y

18. Turpin RE, Rosario AD, Dyer TV. Substance Use and Suicide Attempts Among Adolescent Males Who Are Members of a Sexual Minority: A Comparison of Synthesized Substance-Use Measures. American Journal of Epidemiology. 2020;189(9):900-909. doi:10.1093/aje/kwaa055

19. Bae SM. The prediction model of suicidal thoughts in Korean adults using Decision Tree Analysis: A nationwide cross-sectional study. De Luca V, ed. PLoS ONE. 2019;14(10):e0223220. doi:10.1371/journal.pone.0223220

20. Deo RC. Machine Learning in Medicine. Circulation. 2015;132(20):1920-1930.

doi:10.1161/CIRCULATIONAHA.115.001593

Page $8 / 15$ 
21. Cox CR, Moscardini EH, Cohen AS, Tucker RP. Machine learning for suicidology: A practical review of exploratory and hypothesis-driven approaches. Clinical Psychology Review. 2020;82:101940. doi:10.1016/j.cpr.2020.101940

22. van Mens K, de Schepper C, Wijnen B, et al. Predicting future suicidal behaviour in young adults, with different machine learning techniques: A population-based longitudinal study. Journal of Affective Disorders. 2020;271:169-177. doi:10.1016/j.jad.2020.03.081

23. Jousselme C, Cosquer M, Hassler C. Portraits d'adolescents: Enquête Épidémiologique Multicentrique En Milieu Scolaire En 2013.; 2015.

24. Gradus JL, Rosellini AJ, Horváth-Puhó E, et al. Prediction of Sex-Specific Suicide Risk Using Machine Learning and Single-Payer Health Care Registry Data From Denmark. JAMA Psychiatry. 2020;77(1):25. doi:10.1001/jamapsychiatry.2019.2905

25. Burke TA, Jacobucci R, Ammerman BA, Alloy LB, Diamond G. Using machine learning to classify suicide attempt history among youth in medical care settings. Journal of Affective Disorders. 2020;268:206-214. doi:10.1016/j.jad.2020.02.048

26. Jiang Y, Reilly-Chammat R, Cooper T, Viner-Brown S. Disparities in Health Risk Behaviors and Health Conditions Among Rhode Island Sexual Minority and Unsure High School Students. J School Health. 2018;88(11):803-812. doi:10.1111/josh.12688

27. alcool.be. consommation problematique melange de substances. Published 2021. alcool.be/consommationproblematique-melange-de-substances

28. Khanipour H, Hakim Shooshtari M, Bidaki R. Suicide Probability in Adolescents With a History of Childhood Maltreatment: The Role of Non-Suicidal Self-Injury, Emotion Regulation Difficulties, and Forms of Self-Criticism. Int J High Risk Behav Addict. 2016;5(2):e23675. doi:10.5812/ijhrba.23675

29. O'Connor RC, Noyce R. Personality and cognitive processes: Self-criticism and different types of rumination as predictors of suicidal ideation. Behaviour Research and Therapy. 2008;46(3):392-401. doi:10.1016/j.brat.2008.01.007

30. DeHaan S, Kuper LE, Magee JC, Bigelow L, Mustanski BS. The Interplay between Online and Offline Explorations of Identity, Relationships, and Sex: A Mixed-Methods Study with LGBT Youth. The Journal of Sex Research. 2013;50(5):421434. doi:10.1080/00224499.2012.661489

31. Ybarra ML, Mitchell KJ, Palmer NA, Reisner SL. Online social support as a buffer against online and offline peer and sexual victimization among U.S. LGBT and non-LGBT youth. Child Abuse \& Neglect. 2015;39:123-136. doi:10.1016/j.chiabu.2014.08.006

32. D'Augelli AR, Grossman AH, Salter NP, Vasey JJ, Starks MT, Sinclair KO. Predicting the suicide attempts of lesbian, gay, and bisexual youth. Suicide Life Threat Behav. 2005;35(6):646-660. doi:10.1521/suli.2005.35.6.646

33. Montoro R, Thombs B, Igartua KJ. L'association des dimensions de l'orientation sexuelle, du harcèlement et du suicide: quelles minorités sexuelles sont les plus à risque? smq. 2016;40(3):55-75. doi:10.7202/1034911ar

34. Whitaker K, Shapiro VB, Shields JP. School-Based Protective Factors Related to Suicide for Lesbian, Gay, and Bisexual Adolescents. Journal of Adolescent Health. 2016;58(1):63-68. doi:10.1016/j.jadohealth.2015.09.008

35. Price-Feeney M, Green AE, Dorison SH. Suicidality Among Youth Who are Questioning, Unsure of, or Exploring Their Sexual Identity. The Journal of Sex Research. 2021;58(5):581-588. doi:10.1080/00224499.2020.1832184 
36. Muller A. Virtual communities and translation into physical reality in the 'It Gets Better' project. Journal of Media Practice. 2012;12(3):269-277. doi:10.1386/jmpr.12.3.269_1

\section{Tables}

Table 1. - Description of demographic characteristics 
Variables

\begin{tabular}{|c|c|c|c|}
\hline Total & Homosexual & Bisexual & Heterosexual \\
\hline$n=14265$ & $n=209$ & $n=428$ & $n=13628$ \\
\hline $\mathrm{nb}$ & $\mathrm{nb}$ & $\mathrm{nb}$ & $\mathrm{nb}$ \\
\hline
\end{tabular}

\section{Sociodemographics}

Gender assigned at birth ( $N=14265)$

Female

$\begin{array}{llllllll}7444 & 52.2 & 140 & 67 & 315 & 73.6 & 6989 & 51.3\end{array}$

Male

6821

$\begin{array}{lll}47.8 & 69 & 33\end{array}$

113

$26.4 \quad 6639$

48.7

Age $(\mathrm{N}=14265)$

$<0.0001$

$13-14$

$\begin{array}{llllllll}4273 & 29.9 & 38 & 18.2 & 85 & 19.9 & 4150 & 30.4\end{array}$

$15-16$

$17-18$

$19-20$

Region ( $\mathrm{N}=14265)$

urban

semi-urban

rural area

School

Level of school $(\mathrm{N}=14265)$

$\begin{array}{llllllll}5959 & 41.8 & 82 & 39.2 & 186 & 43.5 & 5691 & 41.8 \\ 3670 & 25.7 & 78 & 37.3 & 145 & 33.9 & 3447 & 25.3 \\ 363 & 2.6 & 11 & 5.3 & 12 & 2.8 & 340 & 2.5\end{array}$

$<0.01$

$\begin{array}{llllllll}3822 & 26.8 & 59 & 28.2 & 108 & 25.2 & 3655 & 26.8\end{array}$

$\begin{array}{llllllll}6625 & 46.4 & 89 & 42.6 & 177 & 41.4 & 6359 & 46.7\end{array}$

$\begin{array}{llllllll}3818 & 26.8 & 61 & 29.2 & 143 & 33.4 & 3614 & 26.5\end{array}$

$<0.0001$

Middle

High

Repeating a school year $(\mathrm{N}=14241)$

Yes

No

Parents

Professional activity of father $(\mathrm{N}=13789)$

$\begin{array}{llllllll}4917 & 34.5 & 43 & 20.6 & 103 & 24.1 & 4771 & 35.0\end{array}$

9348

65.516

$\begin{array}{llllllll}4502 & 31.6 & 71 & 34 & 168 & 39.3 & 4263 & 31.3\end{array}$

$\begin{array}{llllllll}9739 & 68.4 & 138 & 66 & 259 & 60.7 & 9342 & 68.7\end{array}$

$\begin{array}{lllllllll}\text { No } & 2093 & 15.0 & 42 & 20.1 & 101 & 23.6 & 1950 & 14.8 \\ \text { Yes } & 11722 & 85.0 & 167 & 79.9 & 327 & 76.4 & 11228 & 85.2\end{array}$

Professional activity of mother $(\mathrm{N}=14009)$

$<0.001$

$<0.01$ 


\begin{tabular}{lllllllll}
\hline No & 2550 & 18.1 & 55 & 26.3 & 100 & 23.4 & 2395 & 17.9 \\
\hline Yes & 11475 & 81.9 & 154 & 73.7 & 328 & 76.6 & 10993 & 82.1 \\
\hline
\end{tabular}

\section{Mental Health}

Suicide attempts

$<0.0001$

\begin{tabular}{llllllllll} 
No & 12496 & 88.5 & 166 & 80.6 & 272 & 63.8 & 12058 & 89.4 \\
\hline Yes & 1625 & 11.5 & 40 & 19.4 & 154 & 36.2 & 1431 & 10.6
\end{tabular}

Table 2. - Overview of the decreasing ranking of factors for suicide attempts in decision tree

\begin{tabular}{|c|c|c|c|}
\hline \multirow[t]{2}{*}{ Factor } & \multicolumn{3}{|c|}{ Decision tree } \\
\hline & Relative & Efficacy & Rank \\
\hline Parental support & 1.0000 & 10.7341 & 1 \\
\hline Consume alcohol with drugs & 0.8925 & 9.5803 & 2 \\
\hline Sexual experience & 0.7495 & 8.0451 & 3 \\
\hline Real-life friend support & 0.6354 & 6.8207 & 4 \\
\hline Belief that adolescence is an easy period & 0.5952 & 6.3885 & 5 \\
\hline Have met some internet friends in life & 0.5521 & 5.9261 & 6 \\
\hline Satisfaction of health & 0.4605 & 4.9435 & 7 \\
\hline History of ecstasy use & 0.4141 & 4.4445 & 8 \\
\hline Participating in dangerous games & 0.4031 & 4.3274 & 9 \\
\hline Dissatisfaction with some body parts & 0.3533 & 3.7925 & 10 \\
\hline Belief that talking about health is easier with mother & 0.3512 & 3.7697 & 11 \\
\hline Online friend support & 0.3303 & 3.5451 & 12 \\
\hline Belief that eating is pleasure & 0.2976 & 3.1943 & 13 \\
\hline When you look at yourself in a mirror you are happy & 0.2948 & 3.1641 & 14 \\
\hline Living with parents & 0.2807 & 3.0127 & 15 \\
\hline Sexual orientation & 0.2565 & 2.7528 & 16 \\
\hline History of cocaine use & 0.2150 & 2.3076 & 17 \\
\hline Gender assigned at birth & 0.1941 & 2.0836 & 18 \\
\hline Smoking & 0.1791 & 1.9226 & 19 \\
\hline History of amphetamine use & 0.1505 & 1.6151 & 20 \\
\hline
\end{tabular}

Table 3. - Single logistic regression models for suicide attempts 


\begin{tabular}{|c|c|c|c|c|c|c|c|c|c|c|}
\hline \multirow[t]{2}{*}{ Variable } & & \multicolumn{3}{|c|}{$\begin{array}{l}\text { Heterosexual } \\
(n=13628)\end{array}$} & \multicolumn{3}{|c|}{$\begin{array}{l}\text { Homosexual } \\
(n=209)\end{array}$} & \multicolumn{3}{|c|}{$\begin{array}{l}\text { Bisexual } \\
(n=428)\end{array}$} \\
\hline & & OR & $\begin{array}{l}95 \% \\
\mathrm{Cl}\end{array}$ & $\mathrm{p}$ & OR & $95 \% \mathrm{Cl}$ & $\mathrm{p}$ & OR & $\begin{array}{l}95 \% \\
\mathrm{Cl}\end{array}$ & $\mathrm{p}$ \\
\hline \multirow[t]{2}{*}{ Demographics } & Gender female & 2.57 & $\begin{array}{l}2.28- \\
2.90\end{array}$ & $<0.0001$ & 1.00 & $\begin{array}{l}0.49- \\
2.15\end{array}$ & 0.997 & 1.16 & $\begin{array}{l}0.74- \\
1.84\end{array}$ & 0.515 \\
\hline & $\begin{array}{l}\text { Living with } \\
\text { parents }\end{array}$ & 1.74 & $\begin{array}{l}1.50- \\
2.01\end{array}$ & $<0.0001$ & 1.25 & $\begin{array}{l}0.51- \\
2.95\end{array}$ & 0.61 & 0.81 & $\begin{array}{l}0.48- \\
1.35\end{array}$ & 0.414 \\
\hline \multirow[t]{4}{*}{ Relations } & $\begin{array}{l}\text { Parental } \\
\text { support }\end{array}$ & 0.30 & $\begin{array}{l}0.27- \\
0.34\end{array}$ & $<0.0001$ & 0.22 & $\begin{array}{l}0.08- \\
0.51\end{array}$ & $<0.001$ & 0.53 & $\begin{array}{l}0.34- \\
0.80\end{array}$ & $<0.01$ \\
\hline & $\begin{array}{l}\text { Have met } \\
\text { some online } \\
\text { friends in life }\end{array}$ & 0.55 & $\begin{array}{l}0.49- \\
0.62\end{array}$ & $<0.0001$ & 0.38 & $\begin{array}{l}0.18- \\
0.77\end{array}$ & $<0.01$ & 0.70 & $\begin{array}{l}0.47- \\
1.05\end{array}$ & 0.084 \\
\hline & $\begin{array}{l}\text { Real-life friend } \\
\text { support }\end{array}$ & 0.36 & $\begin{array}{l}0.23- \\
0.56\end{array}$ & $<0.0001$ & 0.84 & $\begin{array}{l}0.04- \\
5.42\end{array}$ & 0.877 & 0.78 & $\begin{array}{l}0.29- \\
1.87\end{array}$ & 0.591 \\
\hline & $\begin{array}{l}\text { Online friend } \\
\text { support }\end{array}$ & 1.05 & $\begin{array}{l}0.93- \\
1.18\end{array}$ & 0.424 & 0.45 & $\begin{array}{l}0.20- \\
0.98\end{array}$ & $<0.05$ & 1.22 & $\begin{array}{l}0.80- \\
1.86\end{array}$ & 0.363 \\
\hline \multirow[t]{2}{*}{ Personal life } & $\begin{array}{l}\text { First sexual } \\
\text { activity }\end{array}$ & 2.98 & $\begin{array}{l}2.54- \\
3.51\end{array}$ & $<0.0001$ & 0.81 & $\begin{array}{l}0.35- \\
1.87\end{array}$ & 0.622 & 1.40 & $\begin{array}{l}0.79- \\
2.53\end{array}$ & 0.253 \\
\hline & $\begin{array}{l}\text { Participated in } \\
\text { dangerous } \\
\text { games }\end{array}$ & 2.66 & $\begin{array}{l}2.28- \\
3.08\end{array}$ & $<0.0001$ & 6.57 & $\begin{array}{l}2.51- \\
17.71\end{array}$ & $<0.0001$ & 4.19 & $\begin{array}{l}2.50- \\
7.14\end{array}$ & $<0.0001$ \\
\hline \multirow[t]{4}{*}{ Mental health } & $\begin{array}{l}\text { Dissatisfaction } \\
\text { with some } \\
\text { body parts }\end{array}$ & 3.40 & $\begin{array}{l}2.89- \\
4.02\end{array}$ & $<0.0001$ & 9.17 & $\begin{array}{l}1.87- \\
165.97\end{array}$ & $<0.05$ & 1.22 & $\begin{array}{l}0.62- \\
2.51\end{array}$ & 0.577 \\
\hline & $\begin{array}{l}\text { Belief that } \\
\text { adolescence is } \\
\text { an easy period }\end{array}$ & 0.76 & $\begin{array}{l}0.71- \\
0.81\end{array}$ & $<0.0001$ & 0.73 & $\begin{array}{l}0.50- \\
1.06\end{array}$ & 0.098 & 0.70 & $\begin{array}{l}0.57- \\
0.87\end{array}$ & $<0.001$ \\
\hline & $\begin{array}{l}\text { Belief that } \\
\text { eating is } \\
\text { pleasure }\end{array}$ & 0.44 & $\begin{array}{l}0.39- \\
0.49\end{array}$ & $<0.0001$ & 0.40 & $\begin{array}{l}0.19- \\
0.86\end{array}$ & $<0.05$ & 0.48 & $\begin{array}{l}0.30- \\
0.76\end{array}$ & $<0.01$ \\
\hline & $\begin{array}{l}\text { when you look } \\
\text { at yourself in a } \\
\text { mirror you are } \\
\text { not happy }\end{array}$ & 1.07 & $\begin{array}{l}1.03- \\
1.13\end{array}$ & $<0.01$ & 0.93 & $\begin{array}{l}0.67- \\
1.29\end{array}$ & 0.673 & 1.12 & $\begin{array}{l}0.92- \\
1.36\end{array}$ & 0.271 \\
\hline \multirow[t]{5}{*}{$\begin{array}{l}\text { Consumption } \\
\text { of substances }\end{array}$} & $\begin{array}{l}\text { Consume } \\
\text { alcohol with } \\
\text { drugs }\end{array}$ & 7.93 & $\begin{array}{l}6.29- \\
9.98\end{array}$ & $<0.0001$ & 21.21 & $\begin{array}{l}6.18- \\
98.24\end{array}$ & $<0.0001$ & 7.63 & $\begin{array}{l}3.89- \\
16.17\end{array}$ & $<0.0001$ \\
\hline & $\begin{array}{l}\text { History of } \\
\text { cocaine use }\end{array}$ & 4.29 & $\begin{array}{l}3.29- \\
5.24\end{array}$ & $<0.0001$ & 6.84 & $\begin{array}{l}2.23- \\
22.11\end{array}$ & $<0.001$ & 4.60 & $\begin{array}{l}2.64- \\
8.26\end{array}$ & $<0.0001$ \\
\hline & $\begin{array}{l}\text { History of } \\
\text { ecstasy use }\end{array}$ & 4.55 & $\begin{array}{l}3.55- \\
5.80\end{array}$ & $<0.0001$ & 5.92 & $\begin{array}{l}1.49- \\
25.02\end{array}$ & $<0.05$ & 4.25 & $\begin{array}{l}2.16- \\
8.78\end{array}$ & $<0.0001$ \\
\hline & $\begin{array}{l}\text { History of } \\
\text { amphetamine } \\
\text { use }\end{array}$ & 4.25 & $\begin{array}{l}3.17- \\
5.63\end{array}$ & $<0.0001$ & 4.94 & $\begin{array}{l}1,59- \\
15.38\end{array}$ & $<0.01$ & 6.71 & $\begin{array}{l}3.08- \\
16.24\end{array}$ & $<0.0001$ \\
\hline & $\begin{array}{l}\text { Intensive use } \\
\text { of tobacco }\end{array}$ & 3.26 & $\begin{array}{l}2.68- \\
3.96\end{array}$ & $<0.0001$ & 6.26 & $\begin{array}{l}2.51- \\
15.88\end{array}$ & $<0.0001$ & 3.76 & $\begin{array}{l}2.08- \\
6.98\end{array}$ & $<0.0001$ \\
\hline $\begin{array}{l}\text { Health } \\
\text { condition }\end{array}$ & $\begin{array}{l}\text { Satisfaction of } \\
\text { health }\end{array}$ & 0.28 & $\begin{array}{l}0.24- \\
0.32\end{array}$ & $<0.0001$ & 0.32 & $\begin{array}{l}0.14- \\
0.77\end{array}$ & $<0.01$ & 0.37 & $\begin{array}{l}0.23- \\
0.60\end{array}$ & $<0.0001$ \\
\hline
\end{tabular}




\section{Figures}

A

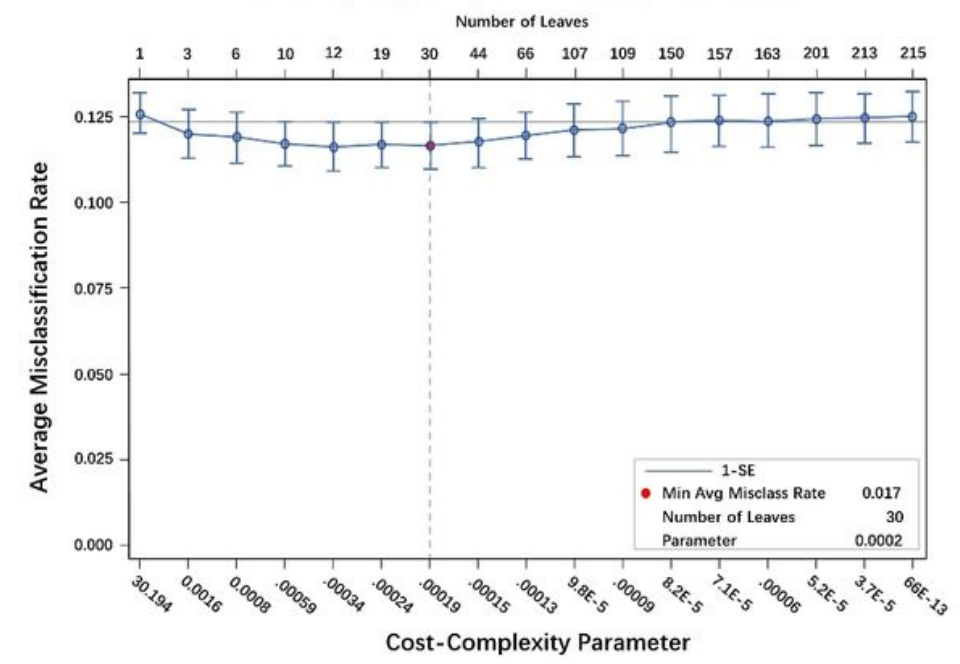

B

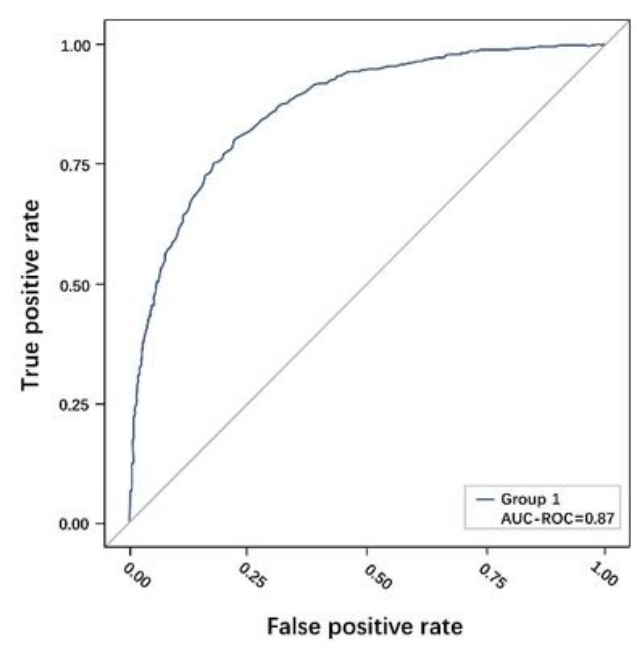

Figure 1

Cost-complexity analysis. Misclassification rate and AUC-ROC curve 


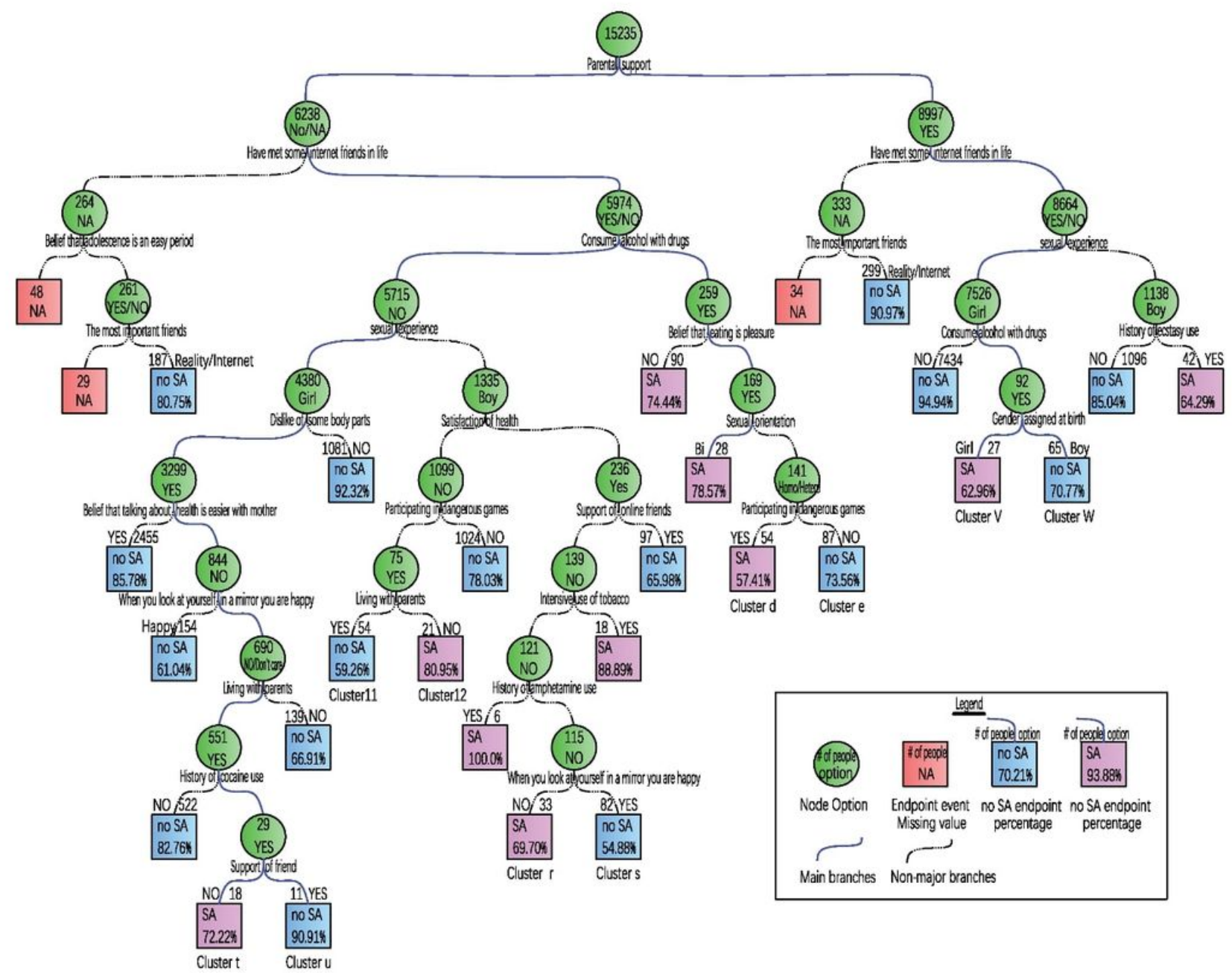

Figure 2

Decision tree model 